\title{
The aesthetic of sustainability: systemic thinking in the evolution of cities
}

\author{
I. Di Carlo \\ Civil, Environmental and Mechanical Engineering University of Trento, \\ (DICAM), Italy
}

\begin{abstract}
Sustainability, while being definitely a new form of humanity, as it has been proposed and dealt with in many urban and landscape projects, lacks often of an essential characteristic of the anthropic space: seduction. We believe that sustainability has to find its own power of seduction if it is to compete successfully with the ambiguous but established charms of the unsustainable city. From all the above it is clear that the importance of the 'aesthetic of sustainability' is fundamental for the success of a new model of green planning not just from an environmental and economic point of view, but, perhaps and most importantly, from a social and mental one.

This paper will investigate the possibility to look at sustainability and aesthetics through the lens of evolutive processes and the complexity theory to inform a new Bottom-Up/Self-Organized approach as a possible morphogenetic process for sustainable city design.

Often criticized as the theory of 'out of control' the complexity theory applied to the urban could instead be the enabler of a new paradigm where the notion of single authorship with intellectual ownership and his aesthetic language is substituted by the concept of a collective and a new aesthetics of choice where aesthetics might recover, according to the evolutionary theory, their essence of an 'adaptive system' and an ecological category.

Keywords: sustainability, urban planning, complexity theory, systemic thinking, multi-agent systems, aesthetics.
\end{abstract}




\section{Introduction}

"It nonetheless remains the case that the immense crisis sweeping the planetchronic unemployment, ecological devastation, deregulation of modes of valorization, uniquely based on profit or State assistance-opens the field up to a different deployment of aesthetic components."

(F. Guattari, Chaosmosis: an ethico-aesthetic paradigm, 1992 [7])

At the moment on the international level there would not seem to be a clear and coded position in order to recognize a specific language and aesthetics in the sustainable design of city and territory.

The urban and landscape scale, which had already introduced the concept of ecology between the 1890 and the First World War with the figure of Patrick Geddes [1], has developed a series of rules more similar to a 'best practice' approach, rather than a real and proactive solution with clearly recognizable aesthetic values. Manifestos like the one of 'One Planet Living Community' or the 'Triple Bottom Line' and many others exist, but they just encode a series of points, a dogmatic and little seductive vision, from a morphological point of view, of a sustainability expressed more through new technological performance rather than through a new urban language.

Existing examples of sustainable urban developments are just necessary ethical actions, but they are lacking of an innovative aesthetic language and they are just partly sustainable.

Sustainability in fact, while being definitely a new form of humanity and more precisely the fourth human metabolic system [2], as it has been proposed and dealt with in many urban and landscape projects lacks often of an essential characteristic of the anthropic space: seduction.

Sustainability has to find its own power of seduction if it is to compete successfully with the ambiguous but established charms of the unsustainable city.

Talking about sustainability as an ethical necessity is a given, but while dealing with this theme, we should also care about aesthetics, style and emotions, the essential elements of seduction that have historically made the city so attractive, particularly the capitalistic city, and have much to do, paradoxically, with excess and exuberance, with surplus production, conspicuous consumption and with waste.

In formal terms when we deal with sustainability we deal as well with that sort of radicalization which is reminiscent of what already happened with modernism towards rationalism, as Frédéric Migayrou [3] reminds us: subverting the classicist logic based on geometry, the humanist balance of proportions directly linked to the human body was substituted by the idea of a normative measurement.

Following the same path: a logic based on composition and tectonicmorphogenetic research has been replaced by one aesthetically impoverished and diminished, but normatively legitimated by an ethically performing technology.

Sustainability, as a matter of fact, contains in its performance some functional rigidity codified by a series of norms placing the ethic as the ultimate irreplaceable value. However, since functional rigidity tends towards chaos rather than 
complexity, while Excellency, understood as the Greek value of kalokagathia (an expression formed by the crasi of the two concepts of beautiful - kalòs - and - kai - good - agathòs, one of Buber's Grundworte :words that have a meaning just if in couple) implies a certain degree of complexity, in a society such as the contemporary one oriented most of all in terms of efficiency, speed and economic gain, the aesthetic value, often anti-functional and anti-economic, tends to be an obstacle exactly because it implies the acceptance of such complexity [4].

From all the above it is clear the importance of the 'aesthetics of sustainability' is fundamental for the success of a new model of green planning not just from an environmental and economic point of view, but, perhaps and most importantly, from a social and mental one. It is the aesthetic as it is envisaged by Guattari and Foucault: 'a way to hint at the creative potential of expression and enunciation that has been silenced by the dominant force of signs and signifiers' [5]. It is an aesthetic paradigm interwoven with ethical and scientific paradigms: 'The new aesthetic paradigm has ethico-political implications because to speak of creation is to speak of the responsibility of the creative instance with regard to the thing created [5].'

\section{The three Ecologies and the importance of the evolutionary approach: aesthetics as an adaptive system}

In the Ecosophical treatise 'The three Ecologies' Guattari was de facto advocating that the increasingly deteriorating condition of human relationships with the socius, the psyche and the environment is due not only to the pollution and the objective damage that belongs to this, but to the most worrying praxes of regarding 'action on the psyche, the socius, and the environment as separate [6]'. Guattari condemned the notion of ecology simply related to the environment in a sort of synonymic equation as too reductive and too dangerous. He added: 'We need to apprehend the world through the interchangeable lenses of the three Ecologies.' Such ecologies are governed by a logic of intensities which "concerns itself solely with the movement and intensity of EVOLUTIVE PROCESSES". This line of thought is important because advocating a sort of 'triplication' implies as well the overcoming of the binary system, the classic polarities and in general the oppositions with all their typical synthesis, therefore it annihilates the dichotomy between ethic and aesthetics, or, in other words, it declares aesthetics as an ethic according to the transversal aspect of the three Ecologies and the aesthetic paradigm always relating to modes of existence and life [7].'

Equally important, this position introduces the idea of ecologies within the neoDarwinian framework of Evolution creating a direct link between ecology and aesthetics.

According to Orians, Professor Emeritus of Biology at the University of Washington, results from existing studies have undoubtedly demonstrated the power of an evolutionary approach to aesthetics: 'Humans have strong emotional responses to living organisms and to natural and human-modified environments. [...] These powerful emotions, which are the foundations of aesthetics, [...] have 
been designed by evolutionary processes'. He specifies that 'aesthetic emotions are a major component of how humans solve problems [8].'

Appleton, Emeritus Professor of Geography at Hull University, on the same subject gives an interesting definition of Beauty as 'the product of interactions between traits of objects and the human nervous system that evolved so that objects we consider beautiful have properties that result in improved performance in some aspect of living if we respond positively to them [9].'

As a Senior Scientist at the International Institute for Applied Systems Analysis in Laxenburg, Marchetti seems to share with the people cited above the idea that aesthetic responses are 'fundamental to the ways in which organisms know about and adapt to the world [10].'

If aesthetic responses evolved because they enabled people to better solve life's problems, exposure to high quality environments should, at least, be restorative and this brings us back to the link between aesthetics and ecologies.

Hence, within the evolutionary approach, it seems to be possible to define aesthetics as an adaptive system and, as such, it 'can function (or continue to exist) only if it makes a continued adaptation to an environment that exhibits perpetual novelty [11].'

\section{The birth of the sustainable agenda in city planning}

The same approach interestingly enough is at the base of the birth of the sustainable agenda in city planning. When in 1915 Patrick Geddes published 'Cities in Evolution' he was trying to fight against the social and environmental chaos and evil of the spontaneous (read: Bottom-Up) sprawl of the city after the industrial revolution.

He was the first one to consider the city as an environment which could influence, positively or negatively the organism it contained and in doing so, although totally unaware of the studies on aesthetics through the evolutionary lens, he was promoting a certain aesthetic quality of the city space and at the same time he was linking social evolution to spatial design and quality of the environment as in 'The three Ecologies'.

Even though his method can be clearly described as a Top-Down approach to planning in a very deterministic, organized and predictable way, his book was also the first publication to shift the accent from a developmental paradigm to an evolutionary one, following the neo-Darwinian framework where small changes can lead to big effects.

The importance that processes acquired in Geddes' studies was also clear in his attempt to understand better the tie between how a city functions in terms of energy and its physical problems, in other words, in a more or less intuitive manner he was trying to investigate the possibility of a method/theory which would link cities' morphologies to the process of their functioning: "[...] urban form should follow the example of plant forms which illustrate how they organize themselves to process energy more efficiently [12]." 


\section{Top-Down vs. Bottom-Up models}

The Top-Down approach promoted by Geddes, even though not initiated by him, was challenged for the first time in the $60 \mathrm{~s}$ by people like Jane Jacobs and Christopher Alexander, who both had rediscovered the potential of small spontaneous changes on a vast scale as per the evolutionary paradigm.

Jacobs in her 'Death and Life of Great American Cities' in 1961 [32] declared that 'the diversity of cities that marked their quality is the diversity that was formed from countless individual decisions, generated from the bottom-up.' The sentence is of particular relevance if we consider proper the definition according to which there is aesthetics 'anywhere the qualitative processes of reception and production, of pleasure and making are examined [13]' because it contains a logic association between quality, hence aesthetics and the evolutionary Bottom-Up model.

In about the same years and all through the $80 \mathrm{~s}$, the formulation of the Complexity Theory gave a final push towards the trends for the re-appropriation of the Bottom-Up model: the essential principle for a complex system to exist is a group of elements that perform independently of one another but nonetheless manage to act altogether. The physical diagram of complexity is the feature of selforganization. Such a passage becomes even more remarkable if seen in concomitance with the interest for clean and renewable energies which seems to flourish in about the same years.

If we look at history as a sequence of different human metabolic systems we see that the type of energy resource men used to draw on in the first two metabolic systems (hunter-gathers societies and agricultural societies) by acting on the biophysical matrix processes in their territory was always a cycle of production and consumption limited to the biosphere. With the access to mineral resources and therefore to the lithosphere, the sustainable cycle of production and consumption got broken because the biosphere was not able to metabolize the unwanted waste coming from consumption of the lithosphere materials [2]. Curiously enough the type of prevailing city models in the first two cases was a Bottom-Up, which was substituted by a Top-Down one after the Industrial revolution.

The research towards new and renewable types of energies, shifted again in the biosphere realm, seems to have been accompanied by a renewed awareness of the potential of the Bottom-Up model of city planning, a more complex and emerging mode of action (Fig. 1).

In this light we could consider the Bottom-Up/Self-Organized approach as a possible morphogenetic process for sustainable city design.

What is exactly the self-organized city and how is this model suitable with the sustainable agenda and most of all with the aesthetics of the sustainable agenda? 


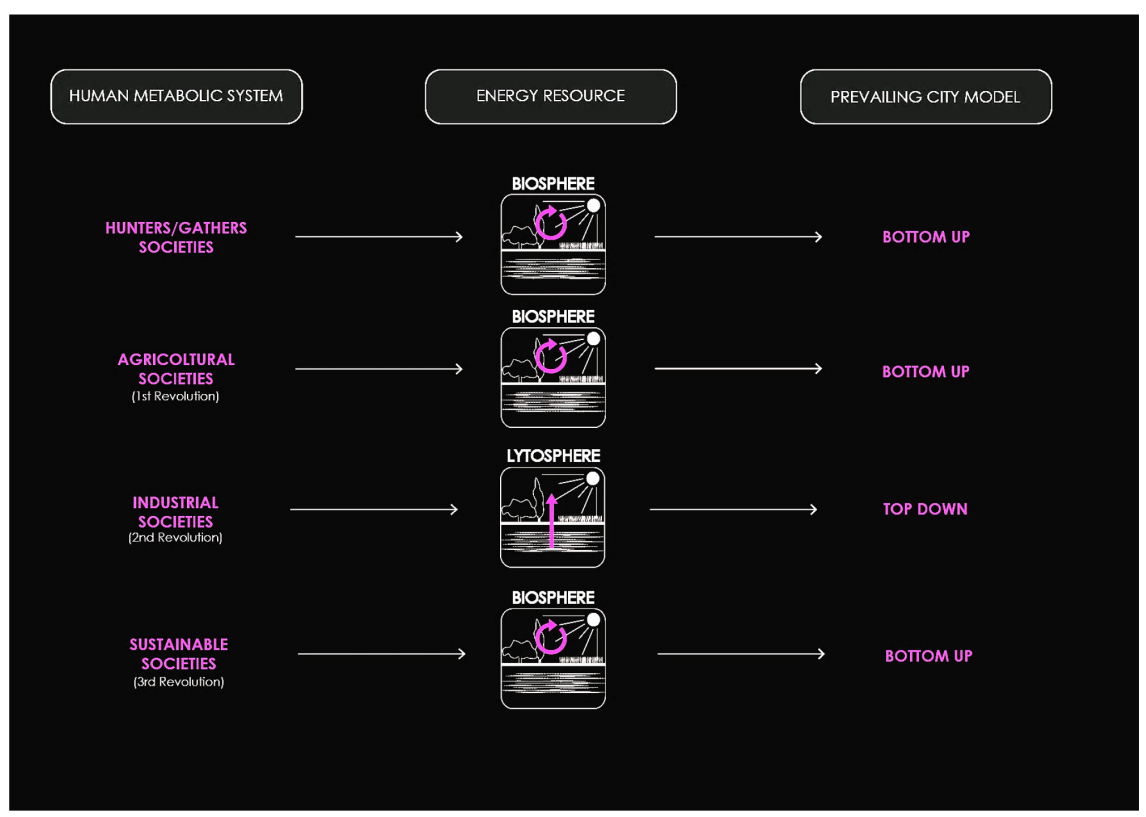

Figure 1: Human metabolic systems and prevailing city models.

According to Peter Longley, Professor of GIS at the Bartlett, UCL, 'selforganized cities are cities that seek to fill their space in the most efficient manner following rules of self-similarity that show how they arrange their parts to conserve and utilize the transport of their energy in the most efficient way'. On the same line Michael Batty, Professor of Planning at the Bartlett and Director of the Centre for Advanced Spatial Analysis, argues: '[The self-organized cities are] models of cities simulating morphologies that are surprising in that their form cannot be anticipated from the assumptions and processes adopted in their representation. [...] [12].'

The main differences between a 'Self-Organized/Bottom-Up' model and an 'Organized/Top-Down' one could be summarized in eight couples of opposite modes as per Fig. 2.

The notion that cities are always 'out of equilibrium' and are constituted by a multitude of bottom-up decisions leads to the recognition of the need to offer solutions which would allow various elements of design to self-organize, guaranteeing a margin of improvisation, so that architecture, city and anthropic landscape could be understood and designed as 'amalgams of processes' which modify and adjust themselves according to some inputs, as if they were selfgenerating systems, open languages of fluid and dynamic aesthetics based on the logic of biotopes, ecosystems and 'loop structures', typical of sustainability. 


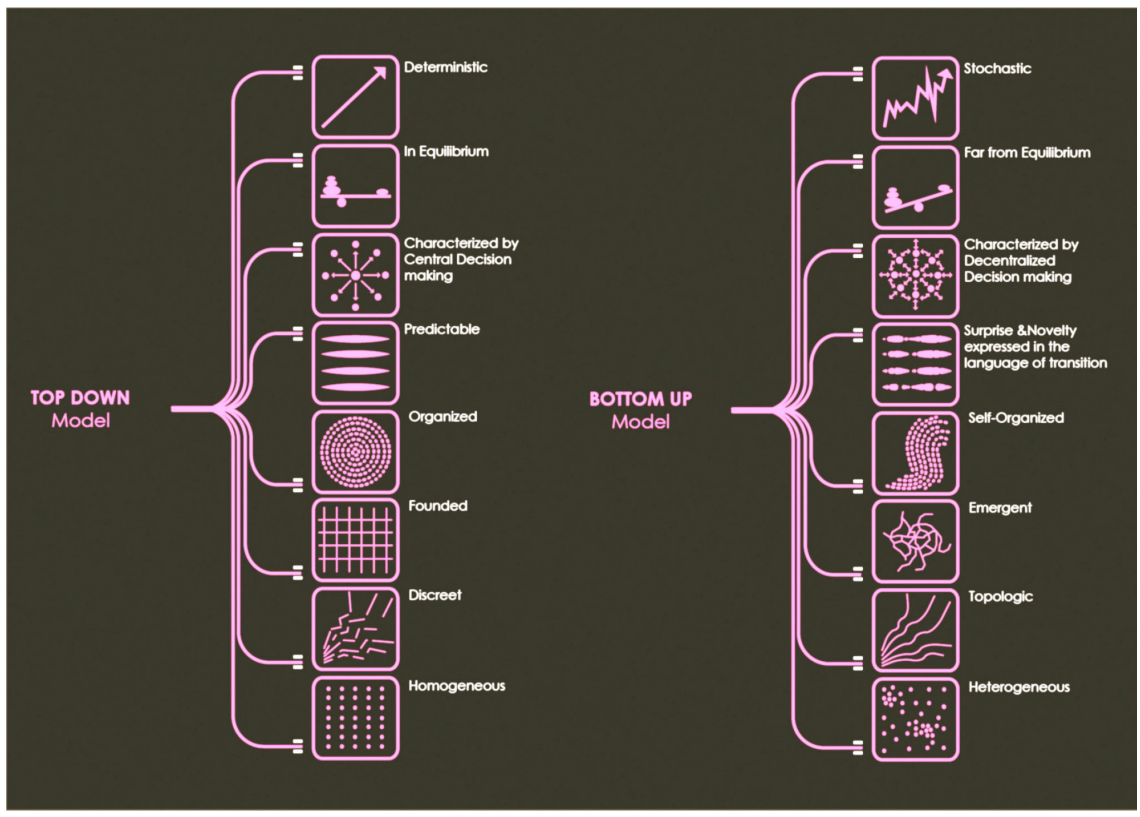

Figure 2: Top-Down vs. Bottom-Up models.

\section{The science of multiplicities and the authorship question}

The bottom-up logic, as we mentioned previously, needs to be situated in the neoDarwinian framework of evolutionary thinking.

Deleuze and Guattari remind us that 'Darwinism's two fundamental contributions moved in the direction of a science of multiplicities: the substitution of population for types and the substitution of rates or differential relations for degrees [14].'

It is what Ernst Mayr, one of the fathers of evolutionary thinking, would later describe as 'Population thinking versus Typological thinking': 'For the Typologist, the type (eidos) is real and the variation an illusion, while for the Populationist the type (average) is an abstraction and only the variation is real [15].'

Variations, differentiations, and multiplicities are categories of paramount importance within the evolutionary paradigm. They differ from the term variants, acceptation more proper to typological thinking, as they imply the replacement of visual sameness with similarity, in fact while variants represent modifications to an original artifact/model, variations do not imply the existence of a primitive, a matrix or an archetype, they rather indicate marking differences of one individual from another of the same species. Most importantly, shifting from biology back to architecture, they embody the passage from typicality to non-standard seriality [16]. It is the passage from the science of models characteristic of a series, where, 
by models, we mean rules, to the science of codes, where by codes, we mean rules; in other words, from types to variables.

Sanford Kwinter perfectly summarized this process when stated that 'The relation of matter and forms are temporal and it is related to the path they have done to get there [17].' In computational terms that path is an algorithm.

Within this scientific framework of complex, emergent, bottom-up logics algorithmic models are being organized to digitally breed cities, dealing with the 'organization, quantification and systematization of quanta of data [18]' and their advent implies a revolutionary approach for what concerns one of the most controversial and debated issues in the discipline of architecture and urban planning: the notion of style and authorship.

In a field like the one of algorithmic morphogenesis, self-organizing and emergent systems are playing a major role in challenging the 'modern notion of architect's full authorial control and intellectual ownership of the end product [18]' and the contribution of the designer to the process could run the risk of being downgraded to a simple breeder [19].

However, we believe that it would be worthwhile to dwell a bit more on a couple of points in order to better understand the implications that concepts like subjectivity and agency could have in morphing the discipline's future.

First, the same notion of complexity, as it has been developed in different disciplines and not only in architecture and urbanism has been modeled and applied initially through the use of Parametric Algorithms (PA) and more recently through Interactive genetic algorithms (IGA) and they imply a sort of dialogue, a notational code, between man and machine. This dialogue would be better described as an interface and has a particular privileged role to play in the production and use of subjectivity as we find it in the definition of the aesthetic paradigm of Guattari's Chaosmosis. An idea of subjectivity strictly linked to the concept of ecology and virtuality. It recalls indeed the designation of machines of virtuality, 'blocks of mutant percepts and affects, half-object half-subject. [...] Not a gestalt configuration, crystallizing the predominance of "good form. It's about something more dynamic, that I would prefer to situate in the register of [...] the autopoietic machine to define living systems [8]'.

From a semiotic and ontological point of view the interface and its autopoietic, self-organizing assemblages are 'incorporeal ecosystems' [8], de facto resembling the notion of virtual ecology, or ecology of values, wished for by Guattari: 'a speech between men and machines that would mark the change from the contemporary world [...] to a world characterized by a generalized ecology ecosophy $-[\ldots]$ as a science of ecosystems, as a bid for political regeneration, and as an ethical, aesthetic and analytic engagement [8].'

The very notion of the interface, together with the one of bottom-up systems, entails concepts like open-endedness, participation, interaction and mass collaboration and reconnects to the concept of Population thinking as the method of reasoning which remind us that the population, the group, the society is the medium for the production of forms, not the single person.

This position in the history of art is neither new nor revolutionary as even in the XVth century Leon Battista Alberti, 'master builder of the Italian Renaissance' 
[20] committed to achieve personal recognition through the affirmation of 'his role above the others' in the construction of a building, believed that creativity was a social and not an individual process [18].

Often criticized as the theory of 'out of control', definition that becomes even more pregnant in terms of critical agency, the complexity theory applied to the urban could instead, in my opinion, be the enabler of a new paradigm where the notion of single authorship with intellectual ownership and his aesthetic language is substituted by the concept of a collective and a new aesthetics of choice or 'aesthetics of decision [21]', where aesthetics might recover, according to the evolutionary theory, their essence of an adaptive system and an ecological category [22]. We would then recuperate that 'flux of participation' evoked by David Abram: 'Our senses are not for detached cognition but for participation, for sharing the metamorphic capacity of things that lure us [29].'

\section{Transdisciplinarity and new models}

There is a need for a new hermeneutics which would bring along a new aesthetics as a property of matter in evolution according to the "fundamental law about the creation of complexity: all the well-ordered systems that we know in the world, all those anyway that we view as highly successful, are generated structures, not fabricated structures [24].'

New models are required in order to breed cities in 'digital laboratory', models that can be borrowed by other disciplines like biology, genetics, economics, cybernetics, botanics, as Jose Louis Sert said "cities [are] living organisms; [they] are born and ... develop, disintegrate and die ... In its academic and traditional sense, city planning has become obsolete. In its place must be substituted urban biology [25].'

The discourse about the urban has already taken advantage of the migration of certain models from other disciplines.

A reference could be for example the loan from biology of sugar-scape models, agent based social simulations that make possible to explore the connection between the micro-level behavior of individuals and the macro-level patterns that emerge from the interaction of many individuals; or allometric models, studying the relationship of body size to shape, anatomy and finally behavior, can be used to link the size and shape of living objects to the networks they use to deliver resources to their parts; or again stigmergic models, mostly interesting within the framework of a sustainable agenda because they represent the social mechanism of coordination based on interaction through local modifications to a shared environment.

This last model has been further enriched in terms of cognitive emergent behaviors when borrowed in turn by IT scientists who introduced the presence of artifacts as environmental modifiers. The research team headed by Prof. Ricci working on the concept of Stigmergy as a MASs (multi-agent systems) technique for realizing forms of emergent coordination in societies composed by simple, non-rational agents, introduced the use of 'suitable engineered artifacts' to explore instead the concept of Stigmergy in the context of societies composed by 
cognitive/rational agents [26].' The standing hypotheses at the base of the study were mainly two: the environment as subject to open interpretation and perception, therefore subject to an aesthetic conventional and collective system of signs and the environment as mediator of behaviors, articulated and composed of artifacts which, subjects to human cognitive activity, assemble the social workspace. Artifacts are therefore entities representing the environment that mediates agent interaction and enables emergent coordination and represent the rationality/intentionality of agents' actions.

In this perspective the environment acquires a key role, acting not only as a container, a passive landscape against which all the interactions occur, but rather as a negotiator and a ruler of interactions promoting the emergence of local and global coordinated behaviors.

This specific research is of particular interest in the field of architecture and urban design because, as Patrick Schumacher rightly points out, since architecture and even more urban design are at the genesis of modes of abstract thinking where conceptual structures and schema can emerge, it follows that architecture sets up social order and in this line becomes explicit the importance of the role of artifacts because 'they are the factors upon which society is built up [27].'

\section{The self-organizing city: evaluation metrics}

Architecture and the city, where city is considered as the Latin concept of Urbs and not Civitas, are to all effects artifacts and "are generally considered to be static, a-biotic components of the constructed or natural ecosystems in which they are situated [28]". They are the physical medium where living subjects exchange relations. Borrowing again the dictionary of biology we could argue that they are the biotopes, ecosystems' components characterized by a-biotic factors with their physical and chemical features but not disjointed from their biotic biological components, biocenosis: both are the indivisible components of an ecosystem.

However, within the framework of systemic thinking a more adept perspective would be to redefine buildings and cities as constructed habitats.

This design approach inherently encourages exploration of the performance potential of incorporating ecological behaviors - multivalent, adaptive, aesthetic, spatial, parametric and systemic - into the design process, constructing 'sensuous ecologies' [29].

In order to pursue this path we need to answer the question: "Is it possible for constructed ecosystems to be developed in symbiotic ways?" According to Mangone and Teuffel [28], this is possible when natural ecosystems and processes are understood as valuable design elements. This perspective reconnects natural and human processes and environments, considering them to be interdependent and in the end indistinguishable. Developing habitats that interweave the natural ecosystem with the constructed ecosystem is one approach that has the potential for creating environments with much more intensity and nuance than current static ones permit [28]. In other words a new aesthetics. 
The challenge though here is how to establish the metric system for evaluating constructed habitats to objectively distinguish parameters and processes that advance, from those that diminish the aesthetic quality of such habitats.

A possible investigation in order to measure a certain degree of success or failure in terms of aesthetics could lead us to borrow the method and the performance metrics from how ecologists measure natural ecosystems as cultural services and non-use values where cultural-cum-service is defined as the 'aesthetic, artistic, educational and/or scientific value of ecosystems [30]' and nonuse values as the ones which 'encompass all values separated from use [31]'.

This could be the path to recover and regain 'the way the senses themselves have, of throwing themselves beyond what is immediately given, in order to make tentative contact with the other sides of things that we do not sense directly, with the hidden or invisible aspects of the sensible [29].'

\section{References}

[1] Vidle A., Whatever happened to Ecology? AD EcoRedux (208), Wiley, London, pp. 24-33, 2010.

[2] Rueda S., Climate Change: urban projects to mitigate greenhouses gases, Proc. of the AFPCN Symposium 'From the past disasters to the climate change challenge in Europe', 27/11/2008, on line $\mathrm{http} / / /$ www.preventionweb.net/files/10566_91actesrisques.pdf

[3] Migayrou F., Non-standard Planning, ArchiLab's Urban Experiments 2000, Thames \& Hudson, 2000.

[4] Zoja L., Giustizia e Bellezza, Bollati Boringhieri Editore, Torino, 2009.

[5] Brunner C., Nigro R., Raunig G., Towards a New Aesthetic Paradigm. Ethico-aesthetics and Aesthetics of Existence in Foucault and Guattari, on line $\mathrm{http}: / /$ molecularbecoming.com/?paged $=2$

[6] Guattari F., The three Ecologies, Continuum International Publishing Group Athlone, July 2000.

[7] Guattari F., Chaosmosis. An Ethico-Aesthetic Paradigm, Indiana University Press, pp. 90-91, 1992.

[8] Orians G. H., An evolutionary prospective on aesthetics, on line http://www.apa.org/divisions/div10/articles/orians.html

[9] Appleton J., The experience of landscape. NY: John Wiley \& Sons, 1975.

[10] Marchetti C., Notes on the limits of knowledge explored with Darwinian logic. Complexity 3, pp. 22-35, 1998.

[11] Holland J., Complex adaptive systems: a Primer, http://www.santafe.edu/media/bulletin_articles/summer_fall1987v2n1.pdf

[12] Batty M., Darwinism, Evolution and the Development of cities, Talk to 2nd Year UG Bartlett Planning Students Thursday, 25 November 2010, UCL Bartlett, London.

[13] Franzini E. e Mazzocut-Mis M., Estetica, Mondadori, Milano, pp. 1-12, 1996.

[14] Deleuze G. \& Guattari F., A thousand plateaus: Capitalism \& Schizophrenia, The Athlone Press, London, pp. 48, 1999. 
[15] Mayr S. E., Evolution and the diversity of life: Selected essays, The Belknap Press of Harvard University Press, Cambridge, Massachusetts, 1976.

[16] Carpo M., The Alphabet and the algorithm, Writing architecture series, The MIT press, Cambridge, Massachusetts, pp. 81-120, 2011.

[17] Kwinter S., Proto_E_cologics Symposium, 2011, on line http://vimeo.com/28810672

[18] Parisi, L., Contagious Architecture: Computation, Aesthetics, and Space, The MIT Press, Boston, 2013.

[19] De Landa M., Deleuze and the use of genetic algorithm in architecture, on line, http://www.egs.edu/faculty/manuel-de-landa/articles/deleuze-geneticalgorithm-in-architecture/

[20] Grafton A., Leon Battista Alberti, Master Builder of the Italian Renaissance, Hill and Wang, New York, 2000.

[21] Shaviro S., Against self-organization; The Pinocchio theory, on line http://www.shaviro.com/Blog/?p=756

[22] Di Carlo I., The aesthetics in the definition of sustainability, Cities in Nature. Eco-urbanism Landscape Architecture, ed. Scaglione Pino, List Lab, Trento, pp. 87-94, 2012.

[23] Abram D., as quoted in Reclaiming Animism, Stengers I., on line http://www.e-flux.com/journal/reclaiming-animism/

[24] Alexander C., The Nature of Order, Book 2: The Process of Creating Life, Centre for Environmental Structure, Berkeley, CA.

[25] Sert J.L., Congrés Internationaux d'Architecture Moderne. (CIAM), 1942, quoted in Time Magazine, November 30, 1942.

[26] Ricci A. and others, Cognitive Stigmergy: a Framework based on Agents \& Artifacts, on line http:/www.academia.edu/277398/Cognitive Stigmergy_Towards_a_Framework_Based_on_Agents_and_Artifacts

[27] Schumacher P., Proto_E_cologics Symposium, 2011, on line http://vimeo.com/28816240

[28] Mangone G. \& Teuffel P., Constructing Sensuous Ecologies: Beyond the energy efficiency and zero carbon argument, Aesthetics of Sustainable Architecture, ed. Sang Lee, 010 Publishers, Rotterdam, pp. 243-258, 2011.

[29] Abram D., The Spell of the Sensuous: perception and Language in a More than human World, New York: Pantheon Books, 1996.

[30] Costanza R. et al. The value of the world's ecosystem services and natural capital, Nature (387), 253-0, 1997.

[31] Goulder \& Kennedy, Valuing ecosystem services: philosophical base and empirical methods, Nature's services: social dependence on natural ecosystems. ed. G.C. Daily, Island Press, Washington, DC, pp. 23-47, 1997.

[32] J. Jacobs, The death and Life of Great American cities, Vintage Books; New York, November 1992. 